\title{
Jovens com deficiência intelectual nas representações sociais de professores de ensino médio
}

\author{
Young people with intellectual disabilities in the social representations of high school \\ teachers
}

\author{
Kátia Rosa Azevedo ${ }^{1}$ \\ Teresa Cristina Siqueira Cerqueira ${ }^{2}$
}

\begin{abstract}
RESUMO: A presente pesquisa teve como objetivo investigar as representações sociais dos professores de ensino médio das escolas públicas de Brasília sobre a inclusão de alunos com deficiência intelectual (DI) e relacioná-la à formação desses professores. Trata-se de uma pesquisa qualitativa, descritivo-interpretativa. Os dados foram obtidos a partir da aplicação do questionário de associação livre de palavras a 115 professores de 11 escolas públicas e procedemos à análise prototípica desses dados com auxílio do software Evoc. Essa análise foi realizada inicialmente com todos os 115 professores e, posteriormente, apenas com aqueles que declararam ter formação em educação inclusiva. Concluímos que as representações sociais de professores estão objetivadas no binômio legítimo, porém, difícil. Assim, o aluno com DI é representado como especial, porém, imperceptível, discriminado e gera desafio e dificuldade para o professor, que se sente despreparado. Essa representação contrasta com a representação social específica de um subgrupo de professores que apresenta formação continuada em educação inclusiva. Para esse subgrupo, o aluno com DI é constituído de necessidades, mas também de potencialidades. Ele é representado como capaz e dificuldade. Os resultados indicam que a informação advinda do curso de formação é valorizada na representação social, contudo, ela adquire sentido não só em função dos elementos cognitivos, mas também dos elementos afetivos.
\end{abstract}

Palavras-chave: representação social; inclusão; deficiência intelectual; ensino médio.

ABSTRACT: This study aimed at investigating the social representations of high school teachers from public schools of Brasilia about the inclusion of students with intellectual disabilities and relate those representations with the training courses of these teachers. Our theoretical framework is based on Social Representations Theory and educational inclusion literature. We applied the free association questionnaire to 115 teachers from 11 public schools and proceed to the analysis of these empirical data using the software Evoc. This analysis was initially performed with all 115 teachers and later, only with those who had training courses in inclusive education. Results indicated that teachers' social representations is objectified in the binomial legal, however, difficult. Thus, students with intellectual disabilities are represented as special, however, imperceptible. They represent challenge and difficulty for teachers who feel unprepared and unmotivated to make changes. This representation contrasted, however, with the social representation of a specific subgroup of teachers who had specific training during under graduation in inclusive education. For this subgroup, students with intellectual disabilities consists of needs, but also of possibilities, so they were represented as capable and difficult. Results indicated that information from the courses is important in that social context, however, it made sense not only in terms of the cognitive but also to affective elements.

Keywords: social representation; inclusive education; intellectual disabilities; high school.

\footnotetext{
${ }^{1}$ Mestre em Educação; Professora da Secretaria de Estado de Educação do Distrito Federal - Brasília, DF, Brasil. E-mail: kati.rosa@yahoo.com.br.

2 Doutora em Psicologia Educacional; Docente da Faculdade de Educação e do Programa de Pós-Graduação da Universidade de Brasília - Brasília, DF, Brasil.
} 


\section{Introdução}

O aluno com deficiência intelectual é considerado atualmente um dos grandes desafios para os professores, que se habituaram a trabalhar com o aluno ideal, dentro de um modelo único de ensino-aprendizagem que desconsidera a diversidade humana e as possibilidades de escolarização de pessoas com deficiência mental (Padilha, 2001). Nesse contexto de proposições, a escola encontra-se em constante tensão entre, por um lado, promover condições que garantam a aprendizagem e o desenvolvimento de sujeitos ativos, e, por outro, manter o status quo de um sistema alicerçado em processos de poder e dominação (Dias \& Oliveira, 2012), com classificações diferentes para os que aprendem e os que não aprendem.

Esse grupo de alunos, que invariavelmente são representados como os que não aprendem, constitui atualmente o maior grupo entre todas as deficiências atendidas nas escolas regulares de ensino fundamental de Brasília. Dos 8.918 alunos com deficiência matriculados no ensino fundamental, 4.400 são alunos com deficiência intelectual (Brasil, 2014). Por outro lado, há um afunilamento no número de matrículas desses alunos no segmento de ensino médio. Isso revela que a despeito da existência de uma política de educação ostensivamente inclusiva, que defende 0 atendimento dos alunos com necessidades especiais nas classes de ensino comum até os níveis mais elevados de ensino, ainda são omissas e pouco explícitas, no contexto da legislação, as formulações acerca da educação de jovens com deficiência intelectual em turmas regulares de ensino médio (Carvalho, 2006). Também é escassa a discussão sobre possibilidades educacionais para essas pessoas no âmbito dos debates e da literatura.

Esse cenário converge para o fato de que a educação da maior parte dessa população (jovens com deficiência intelectual) ainda é responsabilidade de escolas exclusivamente especiais, ligadas às instituições especiais privadas, de caráter filantrópico, ou à modalidade de classe especial dentro das escolas regulares, o que concorre para uma representação da situação educacional dessa população como uma questão pertinente apenas à educação especial.

Considerando esse contexto de adversidades, os poucos alunos com deficiência intelectual que conseguiram acesso ao ensino médio estão em posição de destaque em relação à parcela significativa da sociedade brasileira que não alcança esse nível de escolaridade. Assim, conforme destacam Dias e Oliveira (2012), de alguma forma, eles estão influenciando, com a evidência de seus progressos, mudanças nas concepções acerca da deficiência e de si mesmos.

Nas escolas regulares da Secretaria de Estado de Educação do Distrito Federal, o atendimento especializado desses alunos está condicionado ao laudo médico que se baseia, para definir a Deficiência Intelectual, no Sistema de Classificação Estatística Internacional de Doenças (CID-10); e este é influenciado pelo Sistema 2002 da Associação Americana de Retardo Mental (AAMR). Esse sistema considera a deficiência intelectual como uma incapacidade caracterizada por importantes limitações tanto no funcionamento intelectual como no comportamento adaptativo, expresso nas habilidades práticas, sociais e conceituais, originando-se antes dos 18 anos (AAMR, 2006).

O prognóstico de educabilidade do aluno com deficiência intelectual, em turmas regulares das escolas públicas de Brasília, apoia-se no modelo proposto pela AAMR (2006) anteriormente citado, uma vez que entende a deficiência intelectual não como um atributo 
da pessoa, mas como um estado particular de funcionamento que decorre da qualidade das interações sociais em seu grupo e dos suportes/apoio oferecidos.

Essa proposta converge para os pressupostos teóricos defendidos por Vygotsky (1984) e Mantoan (2002), que entendem que a promoção do desenvolvimento do sujeito com deficiência mental está diretamente relacionada às possibilidades oferecidas a ele na interação social para compensar seu déficit. Dessa forma, quanto mais positivas forem as trocas psicossociais, mais fortalecido será o desenvolvimento do estudante com deficiência intelectual.

Colocada desse modo, a questão da inclusão do estudante com deficiência intelectual se desloca para o seguinte eixo: as representações sociais dos professores como orientadoras da prática pedagógica são centrais para o desenvolvimento desse aluno, visto que se torna impossível conceber trocas favoráveis na prática inclusiva estruturada em representações sociais fundamentadas em um prognóstico que desconsidera a possibilidade de desenvolvimento do aluno com deficiência intelectual.

Dessa forma, estudos sobre representação social de inclusão, na perspectiva de professores, vêm sendo desenvolvidos, contudo a maioria concentra-se no segmento de ensino fundamental, e poucos deles consideram a deficiência intelectual para além da educação infantil, uma vez que a inserção desses alunos nas classes regulares, nas séries finais, ainda é vista como utópica (Cavalcanti, 2007).

Os estudos concentrados no segmento de ensino fundamental indicam que a inclusão do aluno com deficiência é representada como mera inserção do aluno, ou como assistencialismo/caridade. Nesses estudos, a percepção de aluno está ancorada em uma representação hegemônica da normalidade, revelando um sentido de impossibilidade da educação inclusiva. A impossibilidade também se justifica pelo despreparo profissional, pela falta de uma rede de apoio, bem como pela ausência de recursos da escola (Albuquerque, 2007; Carvalho \& Musis, 2010).

Esse cenário revela que de um lado está a educação inclusiva defendida na teoria; de outro, o retrato do cotidiano, no qual muito se fala, mas pouca efetividade tem sido presenciada (Sassaki, 2003), principalmente no que se refere ao estudante com deficiência intelectual, grupo a que os professores mais resistem em educar porque os consideram agressivos (Lima, 2006). Nesse contexto em que a relação educacional se fundamenta pela caridade ou pelo temor, as limitações do aluno com deficiência intelectual são ressaltadas em detrimento de suas potencialidades.

Sendo assim, o professor parece considerar que pouco ou nada pode ser feito para contribuir com a educação desses alunos, e quanto mais debilitadas forem essas trocas, mais lacunar será o desenvolvimento desses educandos. Dessa forma, os alunos com deficiência intelectual estão incluídos no sistema de ensino por força de acordos internacionais como a Declaração de Salamanca (ONU, 1994), porém, pela falta de investimento pedagógico e de trocas sociais eficientes, podem estar excluídos do direito à aprendizagem (ONU, 1994).

A partir dessas reflexões, considera-se que a inclusão do estudante com deficiência intelectual no ensino médio coloca os professores diante de uma realidade que, mais do que mera aceitação de determinações legais, exige uma reflexão sobre quais são as representações sociais elaboradas e compartilhadas entre eles sobre a escolarização desses alunos no espaço escolar. 
Concebendo nessa perspectiva que as representações sociais são dinâmicas, conforme ressalta Moscovici (2003), esse processo dinâmico se configura pela busca em harmonizar, compreender e encontrar pistas sobre o que fazer e como agir em relação ao objeto não familiar (Moscovici, 2003), dentro de um determinado período histórico.

Neste estudo o que se quer é conduzir as reflexões sobre a inclusão do aluno com deficiência intelectual a partir do arcabouço teórico da Teoria das Representações Sociais. As representações sociais são uma forma de conhecimento elaborada e compartilhada socialmente e que contribui para a construção de uma realidade comum a um grupo (Jodelet, 2001). Elas são, ao mesmo tempo, rígidas e flexíveis, consensuais e individuais. Sua característica rígida, proveniente do núcleo central, está associada à memória coletiva. Entretanto, a despeito da rigidez do núcleo central, é importante ressaltar que as representações sociais são suscetíveis de modificação através das variações dos elementos periféricos, constituídos das experiências e das histórias individuais (Abric, 1998). Sob esta ótica, as representações sociais do professor podem estar fortemente vinculadas a sua formação inicial e ou continuada (Dotta, 2006). Ante as constatações relatadas, questionase: quais representações sociais acerca da inclusão de alunos com deficiência intelectual emergem do discurso dos professores de ensino médio de escolas públicas do DF? A formação do professor pode ser determinante na construção de representações sociais favoráveis à prática inclusiva?

Desse modo, o presente trabalho tem por objetivo investigar as representações sociais dos professores do ensino médio de escolas públicas do Distrito Federal sobre a inclusão de alunos com deficiência intelectual no ensino médio e identificar a relação entre representações sociais dos docentes sobre inclusão do aluno com deficiência intelectual no ensino médio e sua formação inicial e continuada.

\section{Método}

Trata-se de um estudo de caráter exploratório, qualitativo, descritivo-interpretativo, alicerçado na abordagem estrutural da Teoria das Representações Sociais (Sá, 1996; Abric, 1998, 2003).

\section{Participantes}

Participaram desta pesquisa 115 professores de ensino médio de escolas públicas de Brasília. Desses professores, 60,8\% têm idade entre 31 e 50 anos de idade. Todos os professores têm formação inicial compatível com a graduação em licenciatura, e $61,7 \%$ deles têm formação continuada, mas apenas $40,8 \%$ coincidem com a formação continuada em educação inclusiva.

\section{Contexto}

Este estudo foi realizado em 11 escolas de ensino médio da rede pública de Brasília, com registros de matrículas de alunos com deficiência intelectual variando entre três a 18 alunos por escola. 


\section{Instrumento}

O objetivo foi o de identificar as representações sociais dos professores por meio de questionário alicerçado na técnica de associação livre de palavras (TALP). O referido instrumento é composto por uma questão de livre associação sobre o tema da inclusão do aluno com deficiência intelectual em que os professores completam a frase: "para você $o$ aluno com deficiência intelectual/mental no ensino médio é: ...", em seis espaços que podem ser constituídos de frases, bem como de palavras singulares. Na questão seguinte, os professores devem listar, dentre as seis frases ou palavras, as três que forem mais relevantes para eles. O questionário finaliza com a solicitação do significado da palavra considerada mais importante. O instrumento contém ainda as seguintes informações: idade, sexo, escolaridade, tempo de docência, disciplina que leciona, experiência anterior com inclusão do aluno com deficiência intelectual, importância da experiência com o aluno com deficiência intelectual, formação específica na área de inclusão, formação inicial e formação continuada.

\section{Procedimentos de coleta e análise dos dados}

Para realizar a coleta dos dados obteve-se autorização do Núcleo de Documentos da Escola de Aperfeiçoamento dos Professores da Educação (Eape), bem como dos diretores das respectivas escolas. A aplicação do instrumento foi feita nos horários de coordenação dos professores com duração média de 30 minutos.

Os dados foram tratados com o auxílio do software desenvolvido por Vergès, denominado Esemble de programmes permettant (Evoc) - versão 2003. Foi realizada nesse estudo, com auxílio do software Evoc, uma análise prototípica, a qual organiza as evocações produzidas de acordo com a frequência e com a ordem de importância da evocação possibilitada pela hierarquização dos termos enunciados pelos sujeitos. 0 cruzamento entre a frequência e a hierarquização das evocações permite a formação de um Quadro de Quatro Casas ou de Quatro Quadrantes, que expressa o conteúdo e a estrutura das representações sociais (Sá, 1996).

O Evoc é um conjunto de 16 programas que realiza dois tipos de análise: a lexicográfica e a categorização por análise de conteúdo. Os programas que constituem o Evoc são os seguintes: Lexique, Trievoc, Nettoie, Rangmot, Listvoc, Aidecat, Rangfrq, Catevoc, Catini, Discat, Tricat, Recodcat, Stalcat, Rangmotp, Selevoc e Complex. Cada um deles executa uma etapa na análise das evocações obtidas, desde a separação por ordem alfabética, correção de erros de grafia, definição de unidades léxicas, lista de distribuição de ordens médias de evocação para todas as palavras, até a distribuição das palavras por frequência (Accioly Júnior, Carvalho \& Raffin, 2011).

\section{Resultados e discussão}

A análise dos dados foi realizada em dois níveis. No nível 1 avaliou-se a estrutura das representações sociais de todos os professores da pesquisa ( $N=115)$, e no nível 2 analisou-se apenas a estrutura das representações sociais dos professores que declararam ter formação específica em educação inclusiva, com carga horária entre 120 e 360 horas ( $N=31$ ). 


\section{Nível 1}

Dos 115 questionários respondidos, o software Evoc identificou 690 elementos citados, dentre eles, 307 diferentes. Desses 307 elementos, formaram-se 19 palavras, que foram distribuídas pelos quatro quadrantes conforme cruzamento entre frequência e ordem média de importância. A média das ordens médias de importância calculada pelo Evoc 2003 foi aproximada para 3,5. A frequência mínima de evocação foi sete, e a frequência intermediária 14. Dessa forma, foram descartados na composição do Quadro de Quatro Casas os elementos com frequência inferior a sete. A partir dessa organização foi possível a construção do Quadro de Quatro Casas sobre o termo indutor: "O aluno com deficiência intelectual em turmas regulares do ensino médio é: ", conforme figura 1.

\begin{tabular}{|c|c|c|c|c|c|c|}
\hline \multicolumn{7}{|c|}{ Frequência mínima: 7} \\
\hline \multicolumn{7}{|c|}{ Frequência intermediária: 14} \\
\hline \multicolumn{7}{|c|}{ Ordem média: 3,5} \\
\hline & Ordem média $<3,5$ & & & Ordem média >: & & \\
\hline Freq. média & Termo evocado & Freq. & $\mathrm{OMI}$ & Termo evocado & Freq. & OMI \\
\hline$>=14$ & $\begin{array}{l}\text { Desafio } \\
\text { Dificuldade } \\
\text { Discriminado } \\
\text { Especial } \\
\text { Imperceptível }\end{array}$ & $\begin{array}{l}18 \\
19 \\
17 \\
17 \\
17\end{array}$ & $\begin{array}{l}2,6 \\
2,0 \\
3,3 \\
3,0 \\
3,4\end{array}$ & $\begin{array}{l}\text { Diferente } \\
\text { Esforçado }\end{array}$ & $\begin{array}{l}14 \\
22\end{array}$ & $\begin{array}{l}3,8 \\
3,7\end{array}$ \\
\hline$>=7 ;<=13$ & $\begin{array}{l}\text { Capaz } \\
\text { Carente } \\
\text { Convívio ensina } \\
\text { Excluído pedagogicamente } \\
\text { Humano } \\
\text { Professor despreparado } \\
\text { Socialização }\end{array}$ & $\begin{array}{r}12 \\
11 \\
12 \\
13 \\
8 \\
12 \\
10\end{array}$ & $\begin{array}{l}3,0 \\
2,0 \\
2,6 \\
2,5 \\
3,2 \\
2,6 \\
3,1\end{array}$ & $\begin{array}{l}\text { Desatento } \\
\text { Inteligente } \\
\text { Lento } \\
\text { Tímido } \\
\text { Vencedor }\end{array}$ & $\begin{array}{r}10 \\
7 \\
12 \\
9 \\
11\end{array}$ & $\begin{array}{l}3,9 \\
4,2 \\
4,1 \\
4,2 \\
3,7\end{array}$ \\
\hline
\end{tabular}

Figura 1 - Quadro de Quatro Casas sobre o termo indutor: "O aluno com deficiência intelectual em turmas regulares de ensino médio é..." ( $\mathrm{N}=115)$. Fonte: Dados da pesquisa.

Na figura acima são apresentadas as palavras evocadas pelo grupo de professores, segundo critério de frequência (F) e ordem média de importância (OMI). Os elementos que compõem o quadrante superior esquerdo do Quadro de Quatro Casas consistem em cognições provavelmente centrais para a representação social estudada (Abric, 2003).

Portanto, verifica-se que as palavras com maior frequência e mais prontamente evocadas, menor ordem média de importância, possivelmente correspondem ao núcleo central das representações sociais, sendo as mais frequentes e mais importantes entre as evocações (Almeida, Lima \& Paixão, 2012).

O núcleo central é a base comum e consensual de uma representação social, aquela que resulta da memória coletiva e do sistema de normas ao qual certo grupo se refere, constituindo-se em prescrições absolutas (Abric, 2003). A partir desse enquadre teórico, conforme se observa na figura 1 , os elementos com características centrais foram: desafio, dificuldade, discriminado, especial e imperceptível, referindo-se ao aluno com deficiência intelectual em turmas regulares de ensino médio nas escolas públicas do DF. Esses elementos integram uma "teoria do senso comum" e é a centralidade deles que dá sentido à 
representação social sobre o estudante com DI, na perspectiva dos professores de ensino médio. Por conseguinte, verificamos que a articulação entre os elementos do núcleo central resume conteúdo representacional centrado na ambivalência legítimo, porém difícil. $E$ sugere uma expectativa rebaixada sobre a possibilidade de escolarização regular dos alunos com DI. Resultado semelhante foi também encontrado em pesquisa realizada por Albuquerque (2007) sobre a representação social de professoras de educação infantil e séries iniciais do ensino fundamental de Recife/PE.

Segundo este estudo, os termos mais recorrentes nos depoimentos dos professores, ao se referirem à inclusão dos alunos com deficiência revelam resistências e impossibilidades para com esse processo. Evidenciam que, embora a inclusão dos alunos com deficiência seja um avanço da legislação em prol da construção de sua cidadania, as representações sociais das professoras estão focadas na resistência e na impossibilidade para desenvolver práticas pedagógicas inclusivas.

No nosso estudo, o elemento mais frequente e prontamente evocado é desafio, com frequência de evocação 18 e ordem média de importância de 2,6, seguido dos elementos dificuldade com frequência 19 e ordem média de importância de 2,0, discriminado com frequência de evocação de 17 e ordem de importância de 3,3 e imperceptível, com frequência de 17 e ordem média de importância de 3,4.

Esse grupo de elementos centrais deixam entrever que a dificuldade em destaque na representação dos professores remete à ideia de complexidade da atuação docente sob influência do paradigma social, segundo o qual a deficiência intelectual não corresponde a um atributo da pessoa, mas, sim, a um estado particular de funcionamento (AAMR, 2002) que decorre do suporte oferecido à pessoa, da qualidade da mediação realizada pelo professor ou pelos colegas de turma. Sob a influência desse paradigma, a dificuldade que antes era considerada própria da pessoa com deficiência se desloca para a escola, que também precisa rever sua atuação e se traduz em dificuldade para o professor. As explicações dos professores sobre os termos evocados no questionário de Associação Livre de Palavras apontam nessa direção:

P1: A dificuldade é que não tem uma forma fechada de você trabalhar com aluno deficiente intelectual, por que uma hora você tem um aluno, outra hora você tem outro.

P7: É muito belo traçar o objetivo, imaginar os resultados, a dificuldade maior é que nem tudo é sucesso, a gente também lida com fracasso.

P13: Eu sinto muita dificuldade, na verdade as coisas são jogadas, no meu caso que leciono espanhol, o espanhol não é bem dado nem pros alunos que não tem nenhuma deficiência.

Nesse contexto de proposições, o aluno com deficiência intelectual, em turmas regulares de ensino médio, constitui um desafio porque desequilibra o ambiente escolar e provoca a necessidade de revisão das práticas pedagógicas convencionais, tendo em vista a busca de novos procedimentos de ensino, novas estratégias metodológicas capazes de atingir o potencial de cada um dos alunos, respeitando suas diferenças (Oliveira, 2005).

Nessa linha de argumentação, Padilha (2001) ressalta que o aluno com deficiência intelectual é considerado atualmente um dos grandes desafios para os professores que se habituaram a trabalhar com o aluno ideal, dentro de um modelo único de ensinoaprendizagem, que desconsidera a diversidade humana e as possibilidades de escolarização de pessoas com deficiência mental. Os professores são, portanto, desafiados em suas 
habilidades pedagógicas até então alicerçadas em práticas de ensino homogeneizadoras, o que se traduz em dificuldade.

Convém ressaltar que nesse contexto de dificuldade e desafio, os professores também reconhecem que o adolescente com deficiência intelectual é alvo de práticas discriminatórias, e, portanto, vítima do preconceito posto em ação. As práticas discriminatórias são sustentadas por ideias preconcebidas, preconceituosas (Branco \& Madureira, 2012), o que pode resultar em baixa expectativa em relação ao desenvolvimento do aluno com DI, desencadeando no professor uma postura de tolerância em relação à presença desses alunos, onde a limitação permanece como o elemento de maior evidência. Ou seja, a ênfase recai na limitação do indivíduo, e não na estrutura organizacional e pedagógica da escola, o que por sua vez justifica a ausência de intencionalidade nas ações pedagógicas.

Sublinhamos com isso que, embora as políticas públicas educacionais busquem viabilizar uma escolarização regular para os alunos com deficiência intelectual, o que inversamente se constatou neste estudo é que esses alunos, no segmento de ensino médio, constituem um grupo imperceptível. Esse elemento remete à ideia de invisibilidade do aluno com DI em turmas regulares de ensino médio, o que corrobora o pensamento de Dias e Oliveira (2012), segundo os quais a deficiência intelectual geralmente não traz a marca corporal identificadora da diferença, o que leva a caracterizá-la pela invisibilidade. A centralidade desses elementos converge para o fato de que os alunos com DI são desconsiderados, ou seja, invisíveis também na sua capacidade de aprendizagem e desenvolvimento, o que conduz ao entendimento de que ele não é considerado, oficialmente, integrante da escola regular. Sendo assim, estudar numa escola inclusiva parece não dar ao aluno com DI a certeza de ser visto como pessoa que perpassa processos de desenvolvimento semelhantes aos seus pares que não têm diagnóstico de deficiência (Freitas, 2007), nem mesmo de livrar-se do estigma oriundo do ensino especial.

O aluno com DI, embora ocupando fisicamente o espaço da escola regular, simbolicamente não parece pertencer a esse espaço. Dessa forma, conforme Albuquerque (2007), a representação social em relação à inclusão desses alunos fica centrada na ideia de simples inserção.

Essa compreensão converge com o pensamento de Carvalho (2006), segundo o qual os alunos com deficiência intelectual são normalmente vistos a partir de um foco único, qual seja: de infantilização de suas formas de ação, e, por isso, se desconsideram suas experiências de vida. Há uma negação em relação aos seus esforços de participação social, bem como se deixa de reconhecer suas possibilidades de ação e de desenvolvimento.

Em geral, ressalta Abenhaim (2009), as pessoas que demonstram habilidades cognitivas aquém do esperado são poupadas das situações desafiadoras e, consequentemente, dos conflitos cognitivos. Isso geralmente decorre da crença dos educadores na incapacidade dessas pessoas, somada a um sentimento de piedade que os leva a acreditar que dessa forma estão evitando um sofrimento desnecessário. Esquecem que os desafios são indispensáveis à aprendizagem.

Lembrando Vygotsky (1997), pode-se afirmar que o desafio está entre a zona de desenvolvimento real e a zona potencial, na zona de desenvolvimento proximal (ZDP). À medida que se desconsidera essa possibilidade de desafio para os alunos com DI, a inclusão deles nesses moldes se traduz em falsa oportunidade. 
Especial é outro termo que também compõe a zona central das representações sociais dos professores e explica o binômio legítimo, porém, difícil. Ou seja, aqui os professores revelam que, a despeito da escolarização de um aluno que é considerado invisível (DI) ser uma prática mediada por discriminação, realizada com dificuldade e que resulta em desafio, a presença desse aluno com DI no contexto da escola regular ainda é considerada especial, portanto, legítima, ainda que por vezes, inócua.

Com isso, é necessário sublinhar que o termo especial parece indicar a zona muda das representações sociais dos professores sobre a escolarização do aluno com DI no segmento de ensino médio. Em outras palavras, o termo especial, considerado politicamente correto para nomear essa população, parece encobrir concepções que não são aceitas pelo conhecimento reificado que circula atualmente no âmbito legal e filosófico sobre inclusão desses alunos. Portanto, saliente-se que o elemento do provável núcleo central que categoriza o aluno com deficiência intelectual como especial, contudo, imperceptível, pode estar escondendo por trás do verniz especial a ideia de incapacidade, carência, falta, impossibilidade, inadequação.

Por conseguinte, a evocação do termo especial conduz à reflexão sobre as mudanças nas formas de designar as pessoas com deficiência. Ou seja, a tentativa de acompanhar as mudanças paradigmáticas e torná-las mais apropriadas, na perspectiva de valorização dos sujeitos pode representar, conforme Pan (2008), apenas um esconderijo de velhas arapucas que impedem que se vejam os reais valores e as tensões que provocam novas formas encobertas de exclusão.

Por outro lado, é importante entender que o conjunto de sentidos consensuais aos quais os professores de ensino médio recorrem para representar a escolarização regular do aluno com DI, tem a função de manter a identidade desses docentes ajustada com os sistemas e valores socialmente e historicamente construídos e de produzir explicações e justificativas para o seu comportamento em face da proposta inclusiva legal e filosoficamente implementada, daí porque apesar do professor ter consciência de que o aluno com DI é imperceptível e discriminado e de que sua escolarização regular pode gerar dificuldade e desafio, esse aluno ainda é considerado especial. Por conseguinte, a ambivalência difícil, porém legítimo, revela a força da pressão normativa impedindo que o professor expresse plenamente seus pensamentos devido aos riscos de julgamento da parte de seus interlocutores. Sugere, portanto, um discurso baseado no politicamente correto, revelando a zona muda das representações sociais dos professores sobre a escolarização regular de jovens com deficiência intelectual no segmento de ensino médio.

No quadrante superior direito, foram identificados os elementos diferente e esforçado. Esse quadrante, conforme Abric (2003), refere-se à primeira periferia da representação social que abarca os componentes periféricos considerados mais relevantes. Possui maiores frequências de evocação, contudo, menor importância para os participantes da pesquisa.

Os elementos dessa periferia nomeiam o aluno com DI como um aluno diferente, que pessoalmente deve ser esforçado. Rastreando o conceito do termo diferente, o entendemos como a qualidade que permite que algo se distinga de outra coisa. $O$ termo deriva do latim differentia e pode ser usado para mencionar a variedade de coisas de uma mesma espécie. Diferente, por conseguinte, é o contrário de igual ou semelhante.

Trazendo esse enquadre conceitual para o contexto dessa pesquisa, avaliamos que os professores parecem evocar a cognição diferente como modalidade incomum de 
aprendizagem, que distingue da de outros estudantes. O estudante com DI é aquele que precisa "suar a camisa" para obter conquistas, precisa ser esforçado. Os fragmentos de três professores, ao explicar a escolha da palavra mais importante no questionário de Associação Livre de Palavras, apontam nessa direção:

P23: Ele é diferente, aprende no tempo dele, do jeito dele.

P57: É um pouco diferente; o aluno sabe que ele tem que ser esforçado pra conseguir.

P102: O aluno com DI é um aluno diferente dos outros, ele não acompanha o ritmo.

No quadrante inferior esquerdo encontram-se os elementos: capaz, carente, convívioensina, excluído pedagogicamente, humano, professor despreparado e socialização. Os elementos dessa casa integram a chamada zona de contraste, e são enunciados por menor quantitativo de sujeitos, os quais, por sua vez, referem-nos como os mais importantes (Abric, 2003). As cognições convívio-ensina, capaz e humano, presentes na zona de contraste, parecem apontar para a existência de um subgrupo marcado por uma expectativa mais favorável à escolarização regular do aluno com DI que apontam para um caráter mais humanista, considerando que, apesar da deficiência, há possibilidades que devem ser exploradas no processo educativo desse aluno.

Portanto, para esse subgrupo, acredita-se que o estudante é capaz e que o convívio do professor com eles acaba por ensinar, em outras palavras: o convívio faz com que os professores, apoiados em experimentos de ensaio e erro, construam suas teorias situacionais, ou seja, teoria aplicável àquele aluno específico dentro daquela turma específica e em relação àquele conteúdo específico. Nessa perspectiva, a demanda do aluno ensina o professor como deve agir em relação a sua própria escolarização. Os fragmentos de dois professores, ao explicar a escolha da palavra ou frase que apontou como a mais importante no questionário de Associação Livre de Palavras deixa entrever essa ideia:

P1: uma metodologia pré-estabelecida eu não tenho, o convívio ensina, eu trabalho por testes, vou testando.

P2: Com certeza a gente aprende na convivência, você vai vendo as particularidades $e$ aprendendo com ele.

Por outro lado, também no quadrante inferior esquerdo, encontram-se os elementos carente, excluído pedagogicamente, professor despreparado e socialização. Pode-se dizer que esses aspectos apontam para percepção da necessidade de preparo do professor para lidar com um aluno que se apresenta carente e excluído pedagogicamente. Com base nesse entendimento, a falta de conhecimento científico por parte do professor reduz a aprendizagem ao improviso pedagógico, à construção de teorias pedagógicas a partir do convívio, conforme podemos inferir dos fragmentos de dois professores, ao explicar a escolha da palavra ou frase que apontou como a mais importante no questionário de Associação Livre de Palavras:

P1: Acho que não fui preparado pra lidar, não me considero capacitado.

P2: Quando o professor tem formação, a evolução do aluno é outra, ele não fica excluído.

Situando a formação do professor na perspectiva da escolarização regular do aluno com DI no ensino médio, Araújo e Bezerra (2011) ressaltam que os referidos alunos vêm sendo recebidos em turmas regulares de ensino médio, mas quase nada se sabe sobre a maneira singular de ensiná-los e de proporcionar-lhes o domínio efetivo de novas competências cognitivas. Indica, com isso, que o arcabouço metodológico para atuar junto 
aos alunos com DI é lacunar. Sendo assim, conforme declara uma professora entrevistada neste estudo: "O aluno com deficiência intelectual em turmas regulares de ensino médio tem aprovação automática, e o critério de aprovação é exclusivamente a deficiência" (Professora 9).

E nesse mesmo contexto de proposições, o elemento socialização, evocado por esse subgrupo, parece indicar que a escola para o aluno com DI tem função prioritária de promover encontros sociais em detrimento da promoção do desenvolvimento das competências acadêmicas, conforme podemos inferir dos fragmentos de dois professores, ao explicar a escolha da palavra ou frase que apontou como a mais importante no questionário de Associação Livre de Palavras:

P1: Aprender mesmo ele não vai, o importante é a socialização.

P2: Esse aluno vem pra escola com objetivo maior de socializar, não preparar para o vestibular.

A periferia distante é composta pelas palavras mais tardiamente evocadas e com menor frequência de evocação. São consideradas na análise de evocação como aquelas que expressam as modulações individuais de uma representação social. Os elementos encontrados na periferia distante foram: desatento, inteligente, lento, tímido e vencedor.

Os alunos com deficiência intelectual são considerados alunos inteligentes $e$ vencedores por terem chegado a um nível mais elevado de ensino. A despeito das dificuldades vivenciadas, de acordo com Dias e Oliveira (2012), esses alunos conseguiram acesso ao ensino médio, o que os coloca em posição de destaque em relação à parcela significativa da sociedade brasileira que não alcança esse nível de escolaridade. Assim, de alguma forma, eles estão influenciando, com a evidência de seus progressos, mudanças nas concepções acerca da deficiência e de si mesmos.

Os elementos lentos, desatentos e tímidos, expressam características percebidas, observadas, depreendidas pelos professores sobre o aluno com DI a partir da prática. Essas cognições parecem revelar as experiências individuais vivenciadas no cotidiano de sala de aula, um conhecimento que é resultado da aproximação com o aluno com DI.

Constata-se, com isso, que os elementos periféricos, constituídos por um número maior de ideias acerca do aluno com DI, fazem a interface entre o núcleo central e as situações e práticas concretas dos professores de ensino médio. Também incorporam as experiências e histórias individuais dos seus membros e se mostram não apenas mais sensíveis à influência do contexto social imediato, mas também mais flexíveis na orientação dos comportamentos que nele se desenrolam (Abric, 1998).

Trazendo esse enquadre teórico para análise dos resultados desta pesquisa, é possível compreender que os elementos periféricos das representações sociais dos professores de ensino médio sobre a inclusão do aluno com DI parecem indicar suas experiências individuais com esse grupo de alunos. Em outras palavras, são conteúdos menos característicos das representações hegemônicas, estáveis, já que revelam novas construções decorrentes de práticas singulares.

Dessa forma, a despeito de o núcleo central estar associado a uma memória coletiva rígida de imutabilidade da deficiência e de invisibilidade do aluno com DI, verifica-se que as representações sociais são suscetíveis de modificações através das variações dos elementos periféricos, que no caso do presente estudo apontam para um conteúdo representacional mais prospectivo em relação à inclusão desse aluno. Em outras palavras, merece destaque o 
fato de que a ideia de imutabilidade da deficiência e de não direito à vida social constitui uma base comum, coletiva e historicamente compartilhada, sobre a pessoa com deficiência intelectual. Essa base, entretanto, se comunica com os novos paradigmas de respeito à diversidade que conduzem os professores a novos conhecimentos e a novas práticas pedagógicas. Nessa perspectiva, de acordo com Menin (2007, p. 124), "em caso de mudança das práticas em relação ao objeto, muda-se, primeiramente, o sistema periférico, e, somente se as práticas forem irreversíveis e perdurarem no tempo, as mudanças acontecerão posteriormente no núcleo central”.

Tomando como análise os elementos periféricos deste estudo e tendo em vista a importância dos cursos de formação na promoção de novas práticas pedagógicas, a seguir serão consideradas as representações sociais exclusivas dos professores com formação em educação inclusiva, para averiguar se os elementos periféricos têm relação com a formação dos professores e suas práticas.

\section{Nível 2}

Nesta segunda parte da análise dos dados, verificou-se a estrutura da representação social dos professores - que declararam ter formação profissional em educação inclusiva entre 120 a 360 horas de duração - sobre a inclusão do aluno com DI no segmento de ensino médio. Essa seleção resultou num total de 31 questionários. Dos 31 questionários respondidos por professores que declararam ter formação em educação inclusiva, 0 software Evoc identificou 186 elementos citados, dentre eles, 98 diferentes. Desses 98 elementos, formaram-se 12 cognições que foram distribuídas pelos quatro quadrantes conforme cruzamento entre frequência e ordem média de importância.

A média das ordens médias de importância calculada pelo Evoc 2003 foi aproximada para 3,5. A frequência mínima de evocação foi quatro, e a frequência intermediária seis. Dessa forma, foram descartados na composição do Quadro de Quatro Casas os elementos com frequência inferior a quatro. A partir dessa organização, foi possível a construção do mencionado quadro, conforme apresentado na figura 2 a seguir.

\begin{tabular}{|l|l|l|l|l|l|l|}
\hline \multicolumn{7}{|c|}{ Frequência mínima: 4} \\
\hline \multicolumn{5}{|c|}{ Ordem média: 3,5 } \\
\hline \multicolumn{5}{|c|}{ Ordem média < 3,5 } & \multicolumn{3}{c|}{ Ordem média >= 3,5 } \\
\hline Freq. Média & Termo evocado & Freq. & OMI & Termo evocado & Freq. & OMI \\
\hline \multirow{5}{*}{$>=6$} & Capaz & 9 & 2,5 & Diferente & 7 & 3,5 \\
& Dificuldade & 8 & 2,3 & Participativo & 8 & 4,1 \\
& Discriminado & 7 & 2,8 & & & \\
\hline \multirow{5}{*}{$>=4 ;<=5$} & Carente & 4 & 2,2 & Ignorado & 5 & 4,0 \\
& Esforçado & 4 & 3,2 & Imperceptível & 4 & 3,5 \\
& Especial & 5 & 2,2 & Isolado & 4 & 4,7 \\
& Excluído & 5 & 2,8 & & & \\
\hline
\end{tabular}

Figura 2 - Quadro de Quatro Casas para professores com formação em educação inclusiva, sobre o termo indutor "O aluno com deficiência intelectual em turmas regulares de ensino médio é..." ( $N=31$ ). Fonte: Dados da pesquisa. 
Capaz é o termo provavelmente central nesse primeiro quadrante, com um total de nove evocações, tendo sido atribuída uma ordem média de importância de 2,5 . Por ter sido muito evocado, pode-se dizer que essa característica pertence a uma opinião de caráter mais coletivo (Sá, 1996). Trata-se, portanto, de um elemento representacional mais comum entre os professores que têm formação em educação inclusiva. Essa cognição, comum entre os professores com formação em educação inclusiva, conduz ao entendimento de que eles reconhecem que os alunos com DI têm capacidade de desenvolvimento e aprendizagem, e revelam, em relação ao estudo 1, uma transição do foco na deficiência para o foco no qual o aluno e suas possibilidades ganham destaque. Esse aspecto relaciona-se à ideia de que os novos entendimentos a respeito da relação entre deficiência, aprendizado e desenvolvimento, que começam a ganhar espaços entre os professores de ensino médio, nos cursos de formação, podem influenciar as representações sociais dos professores em favor da escolarização regular de alunos com DI no segmento de ensino médio.

Essa reflexão corrobora o pressuposto defendido por Jodelet (2001), segundo o qual o acesso à informação relativo ao objeto representado ocorre de forma desigual e varia de acordo com os interesses do grupo social. Nesse sentido, o repertório para acolher determinada representação pode diferenciar-se pela formação que tem cada profissional (Silva, 2008). Em relação a este estudo, o acesso diferenciado à informação sobre a escolarização de alunos com deficiência pode ser fator de diferença nas representações dos professores, tendo em vista a promoção de práticas inclusivas prospectivas.

As representações sociais acerca de um grupo podem influenciar nos comportamentos e atitudes. Sendo assim, uma vez que o elemento capaz revela um conteúdo representacional favorável à escolarização regular do aluno com DI, é possível esperar desses professores práticas prospectivas em relação à escolarização desses alunos centradas na ideia de que, apesar das dificuldades e da discriminação ainda presentes, existem possibilidades que devem ser exploradas no processo educativo desses alunos.

Esse conteúdo coaduna com entendimento atual que a AAIDD (2010) tem sobre a pessoa com DI, a qual enfatiza o aspecto do desempenho em detrimento dos aspectos relativos aos traços clínicos. Busca, com isso, superar a ideia de deficiência intelectual como uma condição estática e permanente, em favor de uma concepção em que o desenvolvimento varia conforme os apoios e os suportes recebidos pelo indivíduo. Sendo assim, o elemento capaz aponta para um entendimento por parte dos professores de que esse aluno é capaz de encontrar novas rotas de desenvolvimento, dependendo do apoio que recebe do meio social.

No quadrante superior direito, foram identificados os termos diferente e participativo. O elemento participativo pode estar relacionado à cognição capaz. Ou seja, o entendimento de que o aluno com deficiência intelectual é capaz de se desenvolver, agir e produzir, inclui a possibilidade de sua participação em sala de aula; daí porque esse aluno que é capaz é também considerado participativo.

Nos quadrantes inferior esquerdo e inferior direito estão presentes os elementos carente, esforçado, especial, excluído; ignorado, imperceptível; isolado, que, conforme discussão no estudo 1, revelam um conteúdo representacional centrado em expectativas desfavoráveis à escolarização regular do aluno com DI. Esses elementos sugerem a existência de um pequeno grupo, dentre os professores com formação em educação inclusiva, cujos elementos da representação social sobre os alunos com deficiência 
intelectual estão centrados na ideia de impossibilidade de escolarização destes últimos. Isso nos remete à ideia de que, a despeito de terem elementos iguais, os dois grupos podem se organizar de modo diverso e talvez terem representações sociais diferentes, visto que têm núcleos centrais diferentes.

Pode-se afirmar, a partir dessas cognições presentes no sistema periférico da representação social dos professores, que, a despeito da formação em educação inclusiva, as representações sociais dos professores não são facilmente modificáveis. Embora na zona central da representação social dos professores com formação em educação inclusiva, os elementos capaz e participativo sugerem um conteúdo representacional alicerçado em expectativas favoráveis à escolarização regular do aluno com DI, o sistema periférico, constituído das experiências e das histórias individuais desses professores, revela variações desfavoráveis que, por sua vez, têm papel fundamental na dinâmica das representações (Abric, 2003).

Essa alternância entre núcleo central com elementos prospectivos e sistema periférico centrados na baixa expectativa sugere que a formação específica em educação inclusiva parece conduzir os professores a uma nova representação social sobre o aluno com DI no ensino médio, conquanto seja um processo lento e não homogêneo. Todo elemento de informação é, então, valorizado na representação, sendo ela uma remodelagem da realidade em função das posições de quem a produziu (Abric, 1998).

Dito isto, somos levados a crer, conforme Gatti (2003), que os conhecimentos dos cursos de formação adquirem sentido ou não em função de complexos processos não apenas cognitivos, mas socioafetivos e culturais, já que os professores são pessoas integradas a grupos sociais de referência nos quais se desenvolvem concepções de educação, de modo de ser, que se constituem em representações e valores que filtram os conhecimentos que thes chegam. Dessa forma, uma formação que produza efeitos reais deve considerar as representações que filtram esses conhecimentos.

\section{Considerações finais}

Diante do exposto, ficou patente que as representações sociais dos professores de ensino médio sobre a escolarização do aluno com deficiência intelectual estão centradas em um conteúdo representacional ambivalente, objetivado no binômio legítimo, porém difícil. Os elementos com características centrais evocados pelos professores no questionário de livre evocação confirmam essa ideia. Foram eles: desafio, dificuldade, discriminado, especial e imperceptível, referindo-se à escolarização do aluno com deficiência intelectual em turmas regulares de ensino médio nas escolas públicas do DF.

O elemento dificuldade, em destaque nas representações dos professores, deixa entrever que, sob a influência do paradigma social, a dificuldade que antes era considerada própria da pessoa com deficiência se desloca agora para a escola, que também precisa rever sua atuação, e se traduz em dificuldade para o professor. O aluno com deficiência intelectual, em turmas regulares de ensino médio, consiste em desafio porque desequilibra - ambiente escolar e provoca um momento de revisão das práticas pedagógicas convencionais e conservadoras. A inclusão desse grupo de alunos é para os professores de ensino médio uma situação não familiar que os instiga a realizarem o que a princípio parece estar além de suas competências ou habilidades. 
Verificou-se também que os professores consideram que os adolescentes com DI são alvo de discriminação, reforçando, com isso, que o preconceito se configura como mediador da relação com alunos com deficiência intelectual. Nessa perspectiva, embora as políticas públicas educacionais procurem viabilizar a escolarização desses alunos em classes regulares, o que inversamente se constatou neste estudo é que alunos com DI constituem um grupo imperceptível. Esse elemento imperceptível remete à ideia de invisibilidade do aluno com DI em turmas regulares de ensino médio. Primeiro porque a deficiência intelectual, geralmente, não traz a marca corporal identificadora da diferença; segundo, porque a perspectiva de que alunos com deficiência intelectual não aprendem leva os professores a não os enxergar, a não os perceber sob o ponto de vista do desenvolvimento e a considerar que quase nada pode ser feito para contribuir com a escolarização desses alunos.

O termo especial compõe também a zona central das representações dos professores e se coaduna com o binômio legítimo, porém, difícil. Ou seja, aqui os professores revelam que, a despeito de a inclusão do aluno com DI ser uma prática mediada por discriminação, realizada com dificuldade e que resulta em desafio, a presença desse aluno com DI no contexto da escola regular é considerada especial, portanto, legítima, ainda que por vezes, inócua.

Com isso, é necessário sublinhar que o termo especial parece indicar a zona muda das representações sociais dos professores sobre a escolarização do aluno com DI no segmento de ensino médio. Em outras palavras, o termo especial, considerado politicamente correto para nomear essa população, encobre concepções que não são aceitas pelo conhecimento reificado que circula atualmente no âmbito legal e filosófico sobre inclusão desses alunos. Portanto, saliente-se que o elemento do provável núcleo central que categoriza o aluno com deficiência intelectual como especial, contudo, imperceptível, esconde por trás do verniz especial a ideia de incapacidade, carência, falta, impossibilidade, inadequação.

Essa base comum, centrada num conteúdo representacional desfavorável à escolarização regular aluno com DI no ensino médio, contudo, contrasta com o elemento capaz, presente no núcleo central das representações sociais específicas de professores com formação em educação inclusiva. Trata-se, portanto, de uma representação mais comum entre os professores que apresentam formação em educação inclusiva. Essa cognição conduz ao entendimento de que os professores com formação continuada em educação inclusiva reconhecem que os alunos com DI têm capacidade de desenvolvimento e aprendizagem, revelando uma transição do foco na deficiência para uma representação na qual o aluno e suas possibilidades ganham destaque.

Convém reiterar que as representações sociais dos professores, por serem o resultado de um encontro muitas vezes indiferenciado entre indivíduo e sociedade, constituem um fenômeno dinâmico. Ressalte-se, com isso, que na medida em que essa base comum alicerçada na ideia de impossibilidade da escolarização regular do aluno com DI, coletivamente compartilhada, se comunica e negocia com a singularidade adquirida na experiência diária do professor com esses alunos, como também se comunica com o repertório adquirido nos cursos de formação profissional desse professor, é possível despertar mudanças de representações. Isso quer dizer que os conhecimentos que chegaram aos professores sobre como proceder na escolarização do aluno com DI, inclusive a própria experiência com o aluno, são modulações individuais com potencial transformador 
das representações sociais não prospectivas sobre a escolarização desse aluno. Apesar disso, é importante lembrar, conforme Menin (2007), que em caso de mudança das práticas em relação ao objeto, muda-se, primeiramente, o sistema periférico; e, somente se as práticas forem irreversíveis e perdurarem no tempo, as mudanças acontecerão mais tarde no núcleo central.

\section{Referências}

AAIDD. (2010). American Association on Intellectual and Developmental Disabilities. Intellectual disability: definition, classification, and systems of supports. Washington, DC: AAIDD.

AAMR. (2006). Associação Americana de Retardo Mental. Retardo mental-definição, classificação e sistemas de apoio - 2002 (10 ed., M. F. Lopes, Trad.). Porto Alegre: Artmed.

Abenhaim, E. (2009). Deficiência mental, aprendizagem e desenvolvimento. In F. Diaz, M. Bordas, N. Galvão \& T. Miranda (Orgs.). Educação inclusiva, deficiência e contexto social: questões contemporâneas (pp. 237243). Salvador: Edufba.

Abric, J-C. (1998). A abordagem estrutural das representações sociais. In A. S. Moreira \& D. C. Oliveira (Orgs.). Estudos interdisciplinares de representação social. Goiânia: AB Editora.

Abric, J-C. (2003). Abordagem estrutural das representações sociais: desenvolvimentos recentes. In P. H. F. Campos \& M. C. da Loureiro (Orgs.). Representações sociais e práticas educativas (pp. 37-57). Goiânia: UCG.

Abric, J-C. (2005). A zona muda das representações sociais. In D. C. Oliveira \& P.H. F. Campos. Representações sociais: uma teoria sem fronteiras (pp. 23-34). Rio de Janeiro: Museu da República (Coleção Memória Social).

Accioly Júnior, H., Carvalho, M. C., \& Raffin, F. N. (2011). Evoc e sua aplicabilidade nas representações sociais no âmbito da saúde. In A. O. Silva, I. do C. C. Costa \& M. C. C. Alves (Orgs.). Investigação em saúde: múltiplos enfoques. Natal: UFRN.

Albuquerque, E. R. (2007). Inclusão de alunos com deficiência nas representações sociais de suas professoras. Dissertação de Mestrado, Programa de Pós-Graduação em Educação da Universidade Federal de Pernambuco, Recife, PE, Brasil.

Almeida, A. M. O. de, Lima, F. R., \& Paixão, D. L. L. (2012). Representações sociais da adolescência por adolescentes e jovens. Revista Psicologia e Saber Social, 1(2), 278-294.

Araújo, D. C., \& Bezerra, G. F. (2011). De volta à teoria da curvatura da vara: a deficiência intelectual na escola inclusiva. Educação em Revista, 27(2), 277-302.

Bardin, L. (2002). Análise de conteúdo. Lisboa: Edições 70.

Branco, A. M. U., \& Madureira, A. F. (2012). As raízes histórico-culturais e afetivas do preconceito e a construção de uma cultura democrática na escola. In A. M. U. Branco \& M. C. S. L. Oliveira (Orgs.). Diversidade e cultura da paz na escola: contribuições da perspectiva sociocultural. Porto Alegre: Mediação.

Brasil. (2008). Ministério da Educação - Secretaria de Educação Especial. Política nacional de educação especial na perspectiva da educação inclusiva. Recuperado de http://www.portal.mec.gov.br/arquivos/pdf/politicaeducespecial.pdf.

Brasil. (2011). GDF - Governo do Distrito Federal - Secretaria de Estado de Educação - Subsecretaria de Planejamento de Inspeção de Ensino - Gerência de Estatística. Censo escolar 2011. Rede Pública. Publicações da SEEDF: Brasília, DF. Recuperado de http://www.se.df.gov.br/?page_id=4521.

Brasil. (2014). GDF - Governo do Distrito Federal - Secretaria de Estado de Educação - Subsecretaria de Planejamento de Inspeção de Ensino - Gerência de Estatística. Censo escolar 2014. Rede Pública. Publicações da SEEDF: Brasília, DF. Recuperado de http://www.se.df.gov.br/?page_id=4521. 
Carvalho, L. R. (2006). Deficiência mental: aprendizagem e desenvolvimento. Estudos, Goiânia, 3(5-6), 473-486.

Carvalho, M. F. (2006). Educação de jovens e adultos com deficiência mental: inclusão escolar e constituição dos sujeitos. Horizontes, 24(2), 161-171.

Carvalho, S. P., \& Musis, C. R. (2010). Representações sociais de professores acerca do aluno com deficiência: a prática educacional e o ideal do ajuste à normalidade. Revista Educação e Sociedade, 31(110) 201-217.

Castro, R. V. (2011). Prefácio. In A. M. O. Almeida, M. F. S. de Santos \& Z. A. Trindade. Teoria das representações sociais, 50 anos. Brasília: TechhoPolitik.

Cavalcanti, A. M. L. (2007). A inclusão do aluno com deficiência mental no ensino médio: um estudo de caso. Dissertação de Mestrado, Programa de Pós-Graduação em Educação da Universidade Federal do Rio Grande do Norte, Natal, RN, Brasil.

CID-10. (1993). Classificação de transtornos mentais e de comportamento da CID-10: descrições clínicas e diretrizes diagnósticas. Porto Alegre: Artes Médicas.

Dias, S. S. de, \& Oliveira, M-C. S. L. (2012). Inclusão escolar de pessoas com deficiência intelectual: linguagem e construção de sentido. In A. M. U. A. Branco \& M-C. S. L. de Oliveira (Orgs.). Diversidade e cultura da paz na escola: contribuições da perspectiva sociocultural. Porto Alegre: Mediação.

Dotta, L. (2006). Representações sociais do ser professor. São Paulo: Alínea.

Franco, M-A. S. (2012). Práticas colaborativas na escola: possibilidades da pesquisa-ação pedagógica. XVI Endipe - Encontro Nacional de Didática e Práticas de Ensino, Unicamp, Campinas.

Freitas, H. C. L. de. (2007). A (nova) política de formação de professores: a prioridade postergada. Educação e Sociedade, 28(100), 1203-1230.

Gatti, B. A. (2003). Formação continuada de professores, a questão psicossocial. Cadernos de Pesquisa, (119), 191-204.

Jodelet, D. (1998). As representações sociais. Rio de Janeiro: Eduerj.

Jodelet, D. (1999). Os processos psicossociais da exclusão. In B. Sawaia (Org.). As artimanhas da exclusão: análise psicossocial e ética da desigualdade social (pp. 56-66). Rio de Janeiro: Vozes.

Jodelet, D. (2001) Representações sociais: um domínio em expansão. In D. Jodelet (Org.). As representações sociais. Rio de Janeiro: UERJ.

Jodelet, D. (2006). Experiência e representações sociais. In M-S. de S. Menin \& A. de M. Shimizu. Experiência e representação social: questões teórico-metodológicas. São Paulo: Casa do Psicólogo.

Lima, F. J. de. (2006). Ética e inclusão: o status da diferença. In Lucia de A. R. Martins, Jose Pires, Glaucia N. da L. Pires \& Francisco Ricardo L. V. de Melo (Orgs.). Inclusão: compartilhando saberes. Petrópolis: Vozes.

Luiz, R. M. F., Pfeifer, L. I., Sigolo S. R. R. L., \& Castanheira, L. N. (2012). Inclusão de crianças com síndrome de down. Psicologia em Estudo, 17(4), 649-658.

Mantoan, M-T. E. (1997). A Integração de pessoas com deficiência: contribuições para uma reflexão sobre o tema. São Paulo: Memnon, Editora Senac.

Mantoan, M-T. E. (1998). Educação escolar de deficientes mentais: problemas para pesquisa e o desenvolvimento. Cadernos Cedes, 19(46).

Mantoan, M-T. E. (2002). Uma escola de todos, para todos e com todos: o mote da inclusão. Recuperado de http://www.lite.fae.unicamp.br/papet/2002/nt/ta1.5.htm.

Mantoan, M-T. E. (2007). Igualdade e diferenças na escola como andar no fio da navalha. Revista do Centro de Educação, 32(2), 319-326.

Menin, M-S. D. S. (2007). O aspecto normativo das representações sociais: comparando concepções. Revista de Educação Pública, 16(30), 121-135.

Moscovici, S. (1978). A representação social da psicanálise. Rio de Janeiro: Zahar.

Moscovici, S. (2003). Representações sociais. Petrópolis: Vozes.

Moscovici, S. (2009). Representações sociais: investigação em psicologia social. Petrópolis: Vozes. 
Oliveira, I. A. de. (2005). Saberes, imaginários e representações na educação especial: a problemática ética da "diferença" e da exclusão social. Petrópolis: Vozes.

Organização das Nações Unidas (ONU). (1994). Declaração de Salamanca sobre princípios, política e práticas na área das necessidades educativas especiais. Salamanca, Espanha, 7-10 de junho de 1994. Recuperado de http://redeinclusao.web.ua.pt/files/fl_9.pdf.

OEA. (1999). Organização dos Estados Americanos. Declaração da Guatemala. Convenção interamericana para a eliminação de todas as formas de discriminação contra as pessoas portadoras de deficiência. Guatemala.

Padilha, A-M. (2001). Práticas pedagógicas na educação especial - a capacidade de significar o mundo e a inserção cultural do deficiente mental. São Paulo: Autores Associados.

Pan, M. A. de S. G. (2008). O direito à diferença: uma reflexão sobre deficiência intelectual e educação inclusiva. Curitiba: IBPEX.

Sá, C. (1996). Núcleo central das representações sociais. Petrópolis: Vozes.

Sampaio, C. T., \& Sampaio, S. M. R. (2009). Educação inclusiva, o professor mediando para a vida. Salvador: Edufba.

Sassaki, R. K. (1997). Inclusão: construindo uma sociedade para todos. Rio de Janeiro: WVA.

Sassaki, R. K. (2003). Vida independente: história, movimento, liderança, conceito, filosofia e fundamentos. Reabilitação, emprego e terminologia. São Paulo: Revista Nacional de Reabilitação.

Schwartz, Y. (2001). Trabalho e educação. Presença Pedagógica, (38), 5-17.

Silva, K. R. X da. (2008). Criatividade e inclusão na formação de professores: representações e práticas sociais. Tese de Doutorado, Universidade Federal do Rio de Janeiro, Rio de Janeiro, RJ, Brasil.

Skliar, C. (2006). A inclusão que é nossa e a diferença que é o outro. In D. Rodrigues (Org.). Inclusão e educação (pp. 15-34). São Paulo: Summus Editorial.

Vygotsky, L. S. (1984). A formação social da mente (3a. ed.). São Paulo: Martins Fontes.

Vygotsky, L. S. (1989). Pensamento e linguagem. São Paulo: Martins Fontes.

Vygotsky, L. S. (1997). Fundamentos de defectologia. Madri: Visor. 